\title{
RESOLUTIONS ON THE DEATH OF DR. S. W. WILLISTON.
}

Dr. Samuel Wendell Williston, who was an early member and fellow of this society and was elected an Honorary Fellow in 1916, died in Chicago, I11., August 30, 1918. He was born in Boston, Massachusetts, July 10, 1852, and had achieved an almost unique position in American Science for the present period in that he had attained distinction in at least three branches of biology.

His interest in entomology was centered mainly in the Diptera in which group he was an ardent worker, an extensive contributor and his influence probably second to no other American entomologist.

Aside from his standing in American entomology his host of friends in all branches of science will remember him most affectionately as a man of the finest human qualities and as a striking example of the possibilities of achievement open to the American youth of high ideals and devotion to science.

The Entomological Society of America desires to place on permanent record its appreciation of his earnest and hearty support of the society, his many and valuable contributions to entomology, his standing as a representative of the best in American science and his loyal friendship and manhood.

$\begin{array}{ll}\text { Committee: } & \text { Herbert Osborn, } \\ & \text { T. H. PARKs, } \\ & \text { J. J. Davis. }\end{array}$




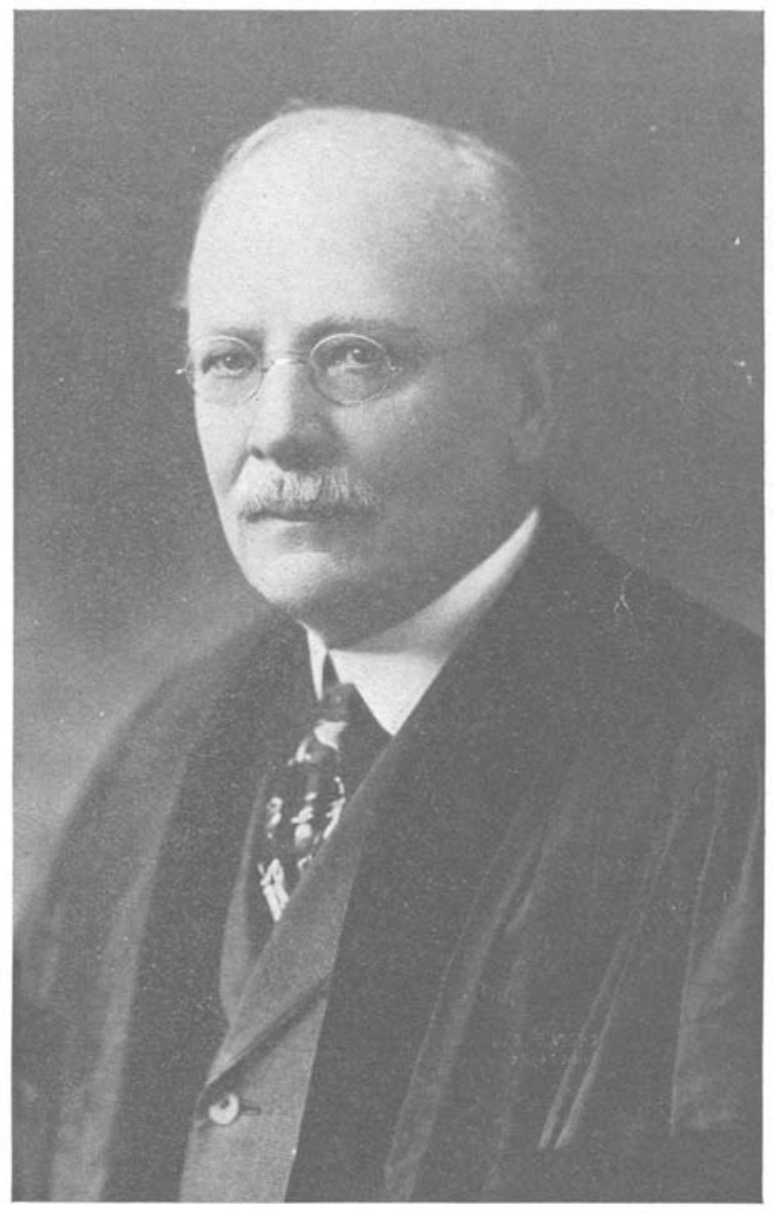

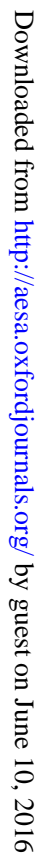

SAMUEL WENDELL WILLISTON

Honorary Fellow, Entomological Society of America 